\title{
Proyecto de investigación para la creación de una fototeca digital y un Sistema de Información para Archivos Fotográficos (SIAF)
}

\author{
Fernando Aguayo, \\ Andrew Green, \\ Lourdes Roca \\ Laboratorio Audiovisual de Investigación Social \\ Instituto de Investigaciones Dr. José María Luis \\ Mora/Conayt/DF-México
}

RESUM EN : Descripción extensa de un proyecto de investigación interdisciplinaria que abarcará las ciencias sociales, la construcción de fuentes y la informática. Dicha investigación genera rá diversos productos, entre ellos, una Fototeca Digital en línea y un Sistema de Información para Archivos Fotográficos (SIAF); estos productos responderán a problemáticas detectadas en el trabajo con las imágenes como fuentes de investigación en M éxico.

PALABRAS C LAVES: Fotografías. Archivos. Sistema de Información. W eb Semántico.

RESUM 0: Trata-se da descrição extensa de um projeto de pesquisa interdisciplinar na área das ciências sociais, documentação e informática. Tal pesquisa gerará produtos, entre eles, uma fototeca digital on-line e um sistema de informação para arquivos fotográficos (SIAF). Esses produtos buscam solucionar os problemas detectados no trabalho com a imagem como fonte de pesquisa no M éxico.

PALAVRAS-C HAVE: Fotografias. Arquivos. Sistema Documental. W eb-semântica.

ABSTRACT: This text describes in detail an interdisciplinary research project in social science, the construction of source materials and computer science. The research project will generate several products, including an on-line Digital Photograph Archive and an Information System for Photographic Archives (or, to use the Spanish acronym, "SIAF"); these products will help to solve problems detected in the way images are used as source material in Mexico.

KEYW O RDS: Photographs. Archives. Documental System. Semantic W eb. 
1. Proyecto Instituto Mora/Consejo Nacional de Ciencia y Tecnología, ciudad de México.
Presentamos un proyecto de investigación interdisciplinaria que abarcará las ciencias sociales, la construcción de fuentes y la informática. Dicha investigación generará diversos productos, entre ellos, una foto teca digital en línea y un Sistema de Información para Archivos Fotográficos (SIAF); estos productos responderán a problemáticas detecta das en el trabajo con las imá genes como fuentes de investigación en México.

La indagación que proponemos constituye la continuación y ampliación de un trabajo que hemos venido realizando desde hace casi dos años en el Laboratorio Audiovisual de Investigación Social (Lais)', cuyos avances incluyen el diseño de las características básicas de la fototeca digital y el SIAF, y la elaboración de un prototipo de este último producto.

Justificación:

- Como centro especializado en investigación social, buscamos fortalecerla desde la academia y promover una cultura de investigación más allá de ese ámbito. Como parte de esta labor, resulta indispensable impulsar el desarrollo de herramientas informáticas al servicio de las ciencias sociales.

- Preocupados por la construcción de las fuentes, su sistematización y el fomento a la circulación de la información, ponemos énfasis en que el documento no es fuente per se, sino que se construye como tal, y esta construcción no consiste en un proceso mecánico.

- N os parece urgente una reflexión acerca de las relaciones que se establecen entre la investigación y las políticas y prácticas de los acervos que resguardan imágenes.

- De ahí la propuesta de trabajar de manera interdisciplinaria desde la investigación social, la construcción y sistematización de sus fuentes, y la investigación informática.

- Con el desarrollo de una fototeca digital y un Sistema de Información para Archivos Fotográficos, daremos pie a un mayor rigor en el trabajo de investigación con imágenes y fomentaremos un mejor apoyo a la docencia.

- También buscamos revertir la dependencia que la investigación tiene hoy de productos informáticos que no siempre responden a sus necesidades y de métodos archivísticos que no se aplican a este tipo particular de documento ni a toda realidad social.

\section{Antecedentes:}

- Investigación realizada entre 2001 y 2002 sobre los usos de lo visual en la investigación social permitió detectar el contraste entre 
las prácticas discursivas de los archivos y la realidad que presentan, sobre todo en materia de catalogación y difusión de sus acervos.

- Propósito del Lais por a tender mejor al proceso de definición integral sobre lo que es un archivo fotográfico, en base a los tres ejes que debe a tender: preservación, catalogación y difusión de sus acervos.

- La institución más importante en este terreno en M éxico es el Sistema $\mathrm{N}$ acional de Fo to tecas $\left(\right.$ Sinafo ${ }^{2}$ ), que propone un ambicioso proyecto para normalizar la organización, preservación, catalogación y difusión de los archivos fotográficos. Los logros en la preservación de acervos gráficos por parte de esta institución son indiscutibles, lo mismo que la calidad en la reproducción fotográfica y la generación de propuestas en ambos campos; sin embargo, por la falta de procesos de investigación, presenta importantes limitaciones en el terreno de la catalogación y difusión de los acervos. Como se ha señalado en otros trabajos ${ }^{3}$, la falta de documentación en los procesos de catalogación se refleja en los modos de representación textual de las imágenes y en su consulta a través de programas informáticos que no responden de manera efectiva a búsquedas y necesidades de la investigación. El laboratorio ha desarrollado una colaboración con varios archivos que pertenecen al Sinafo ${ }^{4} \mathrm{y}$, en caso de que éste reto me las propuestas que a quí planteamos, también podría contribuir a consolidar muchas de las metas que se propone en el rubro de catalogación y el de difusión.

Hipótesis:

La imagen ha sido resguardada por su valor comercial, simbólico y/ 0 estético y no por su valor epistémico, debido a que se ha confundido al patrimonio cultural nacional como algo que debe venderse para preservarse y lamentablemente las acciones al respecto han tomado este cauce.

Como las sociedades nunca son estáticas, los archivos fo to gráficos no sólo pueden sino deben estar abiertos a la permanente transformación ${ }^{5}$. Proponemos generar un espacio amplio de reflexión sobre este campo - en el que se precisen las funciones de estos acervos y se adopten medidas para que éstas se cumplan fuera del ámbito comercial - porque sólo a sí podremos revalorar el valor epistémico de la imagen y fomentar que se adopte una política de patrimonio nacional no comercial.

O bjetivos generales:

1. Realizar una investigación profunda acerca de las prácticas sociales de creación y conservación de fondos fotográficos.

2. Recuperar acervos y colecciones inéditas, para fomentar su construcción como fuentes de investigación, atendiendo de forma
2. Que integra a 17 archivos del país. Véase $<$ ttp://www.cnca. gob.mx/cnca/inah/ac ervos/sinafo.html>.

3.Véase AGUAYO; ROCA, 2004.

4. Con la Fototeca $\mathrm{Na}$ cional se ha colaborado en la documentación de su acervo de ferrocarriles del siglo XIX y con la Coordinación Nacional de Monumentos Históricos se trabaja actualmente en la catalogación de las imágenes del Zócalo de la ciudad de México.

5. Desde luego es importante no olvidar que la creación de archivos de imágenes es una actividad que requiere de muchos gastos en todos los niveles de su actividad, lo que en parte explica las decisiones que se han tomado acerca de vender las reproducciones a los usuarios. Sin embargo, es necesario adoptar otras medidas para salvar estos vestigios históricos invaluables para que nos sirvan en nuestro trabajo de investigación y no sólo recurrir a la venta de las piezas, pues esto únicamente ha fomentado su uso y revaloración comercial y estética, mas no epistémica.Además no debemos perder de vista que la preservación de imágenes (conservación, restauración, almacenamiento) no se resuelve con los procesos de digitalización, aunque al parecer ésta facilita algunas tareas. 
6. De la que podemos conocer experiencias en otros espacios, como losque incluyen las referencias acerca de la informática, las humanidades y las ciencias sociales al final de este texto.

7. Los archivos fotográficos más consolidados en México han promovido modelos catalográficos en los que priman numerosas deficiencias, Io cual nos ha alejado de procesos serios de normalización en lacatalogación. En los documentosque estos archivos han generado al respecto se citan una serie de normas internacionales que no se corresponden con las prácticas y los modelosque proponen.Véase SINAFO, 2000. Con una preocupación particular por los archivos con menos recursos, nos parece importante señalar que la adopción del Siaf implica atender aspectos normalizados de trabajo con las representacions textuales y no la imposición de modelos. Las divergencias en la forma de representar textualmente las imágenes y la negativa a abandonar modelos de fichas textuales, no provienen de posturas claras en torno a la adopción de teoría en el campo de la archivonomía, por lo que este proyecto también busca promover la discusión en este campo, a la vez que demuestra la posibili- prioritaria las colecciones particulares, que son claramente las que presentan mayores necesidades.

3. Fomentar una filosofía de preservación de estos materiales tanto dentro como fuera de la academia.

4. Promover la concepción de los a rchivos como patrimonio público y accesible.

5. Fomentar la implantación de labores de investigación en los archivos mismos para impulsar un mejoramiento de sus prácticas de catalogación y difusión, a partir de la promoción de una visión integral sobre lo que debe ser un archivo fotográfico.

6. Contribuir a la profesionalización de los archivos fotográficos.

7. Propiciar el libre flujo de la información para la investigación.

8. Estructurar dicha información de una manera rigurosa a la vez que flexible para su recuperación y manipulación.

9. Desarrollar herra mientas informáticas que posibiliten los puntos 2 al 8 , respondiendo a necesidades reales de la investigación y sin costos estra to sféricos.

10. Promover el trabajo en grupo a través de redes horizontales.

11. Sentar las bases curriculares para el desarrollo y la incorporación de una formación integral en este campo en los programas educativos de nivel superior en ciencias sociales y humanidades.

12. Promover una filosofía de encuentro entre la investigación social e informática ${ }^{6}$.

Productos de la investigación interd iscip lina ria

La investigación interdisciplinaria que se propone realizar generará los siguientes productos:

1. La fototeca digital en línea.

Se trata de un sitio W eb que permitirá la consulta en línea de a cervos fotográficos. Estará integrada por imá genes originales e información textual relacionada (fichas) pertenecientes a múltiples fototecas ${ }^{7}$. Además, la fo to teca digital ofrecerá a los investigadores la posibilidad de compartir sus observaciones acerca de las imágenes y los textos que las refieren.

2. El Sistema de Información para Archivos Fotográficos (SIAF). 
Software que se creará para implementar la fototeca digital, el cual se desarrollará y estará disponible para quienes lo desean emplear, por medio del sistema conocido como "Softwa re Libre".

3. Una estructura de información que permitirá vincular diversas fichas catalográficas.

La necesidad de manejar simultáneamente varios tipos de ficha surge a raíz de la falta de consenso sobre cómo catalogarlas imágenes y la diversidad de fichas empleadas en los catálogos existentes ${ }^{8}$.

4. Artículos, cursos, ponencias y conferencias que darán a conocer los resultados de la investigación.

Funciones de la fototeca digital en línea

Las funciones que ofrecerá la fototeca digital se dividen en dos categorías: (1) las que podrán emplear los usuarios en general, y (2) las que estarán disponibles únicamente para quienes tendrán bajo su responsabilidad la administración de los datos de una o más colecciones fotográficas.

Funciones disponibles para los usuarios en general:

- Ver en pantalla las imágenes y los datos en formato textual correspondientes.

- N avegar por conjuntos de imágenes.

- Realizar búsquedas sencillas y a vanzadas.

- Personalizar qué información se incluye en los listados de imágenes localizadas por el usuario. (Al realizar una búsqueda el usuario recibirá un listado de imágenes, el cual contendrá una ficha "abreviada" de cada una de éstas. El usuario podrá determinar qué datos aparecerán en esa ficha resumida, según sus propias necesidades de investigación).

- Intercambiar con otros usuarios las observaciones acerca de las imá genes y los datos catalográficos.

- Exportar los datos de la fototeca hacia otros formatos y programas.

N ota: el acceso a las imágenes y la información en forma to textual podrá restring irse con base en varios mecanismos (contraseña, aceptación de términos de uso, posibilidad de ver mas no exportar los datos, etcétera) para hacer cumplir las disposiciones de los autores y los acervos acerca de la difusión y empleo de dicho material. dad de trabajar con fichas divergentes cuando así se decide.

8. Para lograr esto se elaborará una ontología, es decir, una representación formal de conceptos y las relaciones entre ellos; dicha ontología constituirá una suerte de puente entre las diversas fichas que manejará el Siaf. En el presente trabajo no se profundiza sobre las implicaciones archivológicas de esta propuesta; para una aproximación a una parte de los problemas de ese ámbito que se relacionan con el presente proyecto, véase GREEN, 2003. 
Funciones adicionales, disponibles sólo para los responsables de los datos de una o más colecciones fotográficas:

- Capturar y actualizar los contenidos a través de la red.

- Configurar los criterios para el acceso a las imágenes así como la información que se registra como texto.

- Como ya se mencionó, estas funciones actua rán sobre colecciones de imágenes catalogadas con fichas divergentes. Esto será posible gracias a una nueva tecnología conocida como el "W eb Semántico", la cual se describe a continuación.

W eb Semántico

El W eb Semántico (W S) es un proyecto del W orld W ide W eb Consortium, organismo internacional que coordina el desarrollo de normas y tecnologías para la Internet. Fue creado en 1998 por Tim Berners-Lee, uno de los inventores del W eb que hoy conocemos. El W $S$ retoma conceptos que fueron desarrollados en distintos ámbitos, entre ellos, la biblioteconomía, la informática social científica y la inteligencia artificial.

Esencialmente, el W S mejora la organización de los datos que se almacenan en una máquina, de tal manera que un mayor porcentaje de los significados puedan ser manejados y comunicados a uto máticamente (De a hí viene el nombre "W eb Semántico"). Se espera que esto permita incrementar la eficacia de la gestión de datos en Internet y otros ámbitos de la informática.

EI SIAF utilizará varios componentes del W S, principalmente el Marco para la Descripción de Recursos (RDF) y el Lenguaje para 0 ntologías W eb (O W L).

Comparación entre el W eb Semántico y un sistema de información tradicional

Actualmente, la mayoría de los programas que se emplean para gestionar grandes cantidades de información interrelacionada se basan en una tecnología llamada "Sistema de Base de Datos Relacional" (RDBS). Se trata de un mecanismo mucho más antiguo que el W eb Semántico; ha funcionado eficazmente en muchísimas aplicaciones pero también tiene limitaciones severas, sobre todo en cuanto a las posibilidades que ofrece para la estructuración de los datos. Estas barreras resultan aún más evidentes cuando uno intenta emplear un RDBS para manipular información de tipo cualitativo.

El rasgo fundamental de un RDBS es que organiza toda la información en una serie de tablas. En muchos programas, éstas se ocultan del usuario y forman parte del mecanismo interno que se usa para almacenar los datos. Para presentar 
la información al usuario, el programa primero extrae ésta de las tablas, la transforma a un formato sencillo de entender y finalmente la despliega en pantalla.

La Figura 1 muestra una estructura típica de un RDBS. En este ejemplo simplificado, los datos interrelacionados se almacenan en tres tablas: una de libros, otra de imágenes y una tercera de autores.

Incluso en este caso, podemos notar que mucha información importante no se registra debidamente. Por ejemplo:

- Este RDBS no da cuenta del parentesco entre los significados de las columnas "Autor" en las tablas "Libros" e "Imá genes" (En ambos casos, se trata del creador de algo).

- Tampoco da cuenta del parentesco entre los sujetos principales de las tablas "Libros" e "Imágenes" (A mbas tablas se refieren a obras intelectuales).

- El sistema no registra que las columnas "Fecha" y "Fecha de nacimiento" son similares en el sentido de que las tres señalan el año de un acontecimiento.

En cambio, el W eb Semántico ofrece la posibilidad de organizar los datos con base en una estructura mucho más compleja y sutil. En vez de un conjunto de tablas, se almacena un conjunto de afirmaciones, con significados e interrelaciones claramente definidos.

\begin{tabular}{|l|l|l|}
\hline \multicolumn{3}{|c|}{ Libros } \\
\hline \multicolumn{1}{|c|}{ Título } & \multicolumn{1}{|c|}{ Autor } & Fecha \\
\hline $\begin{array}{l}\text { México } \\
\text { Pintoresco }\end{array}$ & Brehme, Hugo & 1923 \\
\hline $\begin{array}{l}\text { México } \\
\text { Ilustrado }\end{array}$ & $\begin{array}{l}\text { Southworth, } \\
\text { J.R. }\end{array}$ & 1903 \\
\hline $\begin{array}{l}\text { México: A } \\
\text { General Sketch }\end{array}$ & Barrett, John & 1911 \\
\hline
\end{tabular}

\begin{tabular}{|l|l|l|}
\hline \multicolumn{3}{|c|}{ Imágenes } \\
\hline \multicolumn{1}{|c|}{ Descripción } & \multicolumn{1}{|c|}{ Autor } & Fecha \\
\hline $\begin{array}{l}\text { Palacio Nacional } \\
\text { desde Catedral }\end{array}$ & Brehme, Hugo & 1914 \\
\hline $\begin{array}{l}\text { Palacio Nacional } \\
\text { desde Catedral }\end{array}$ & $\begin{array}{l}\text { Kahllo, } \\
\text { Guillermo }\end{array}$ & 1900 \\
\hline
\end{tabular}

\begin{tabular}{|l|l|l|}
\hline \multicolumn{3}{|c|}{ Autores } \\
\hline Nombre & \multicolumn{1}{|c|}{$\begin{array}{c}\text { Lugar de } \\
\text { Nacimiento }\end{array}$} & $\begin{array}{c}\text { Fecha de } \\
\text { Nacimimiento }\end{array}$ \\
\hline $\begin{array}{l}\text { Brehme, } \\
\text { Hugo }\end{array}$ & $\begin{array}{l}\text { Eisenach, } \\
\text { Alemania }\end{array}$ & 1882 \\
\hline $\begin{array}{l}\text { Kahlo, } \\
\text { Guillermo }\end{array}$ & $\begin{array}{l}\text { Baden-Baden, } \\
\text { Alemania }\end{array}$ & 1872 \\
\hline
\end{tabular}

\section{La información se almacena en uma} serie de tablas.

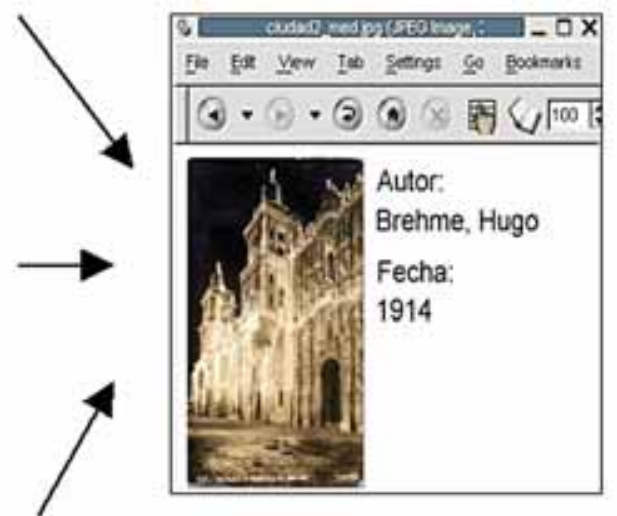

De éstas se extraen los datos que se presentan al ustuario.

Figura 1 - Estructura tipica de un RDBS. 
La Figura 2 muestra, también de manera simplificada, un ejemplo de un fragmento de una red de significados construida con base en los mecanismos del W eb Semántico. Si bien la información que los sistemas de este tipo pueden almacenar acerca de un objeto determinado es menor en cantidad y complejidad que los significados que podría manejar un ser humano acerca del mismo objeto, de todas maneras con el W eb Semántico las computadoras registran mucha más información que con los RDBS, y lo hacen con base en estructuras más elaboradas. Esto tiene múltiples beneficios, sobre todo en cuanto a las funciones que se pueden ofrecer al usuario final.

Ventajas de emplear el W eb Semántico en la fototeca digital

Usar el W S como base para la fototeca digital tiene numerosas ventajas específicas. Las más importantes se describen a continuación:

- Facilidad para integrar fichas divergentes en un mismo sistema. La red de significados permitirá registrar rigurosamente en la máquina las diferencias y puntos en común de las fichas que se emplearán. Con esto, se podrá integrar a la fototeca digital funciones que manipularán automáticamente las fichas con base en dichas diferencias y similitudes.

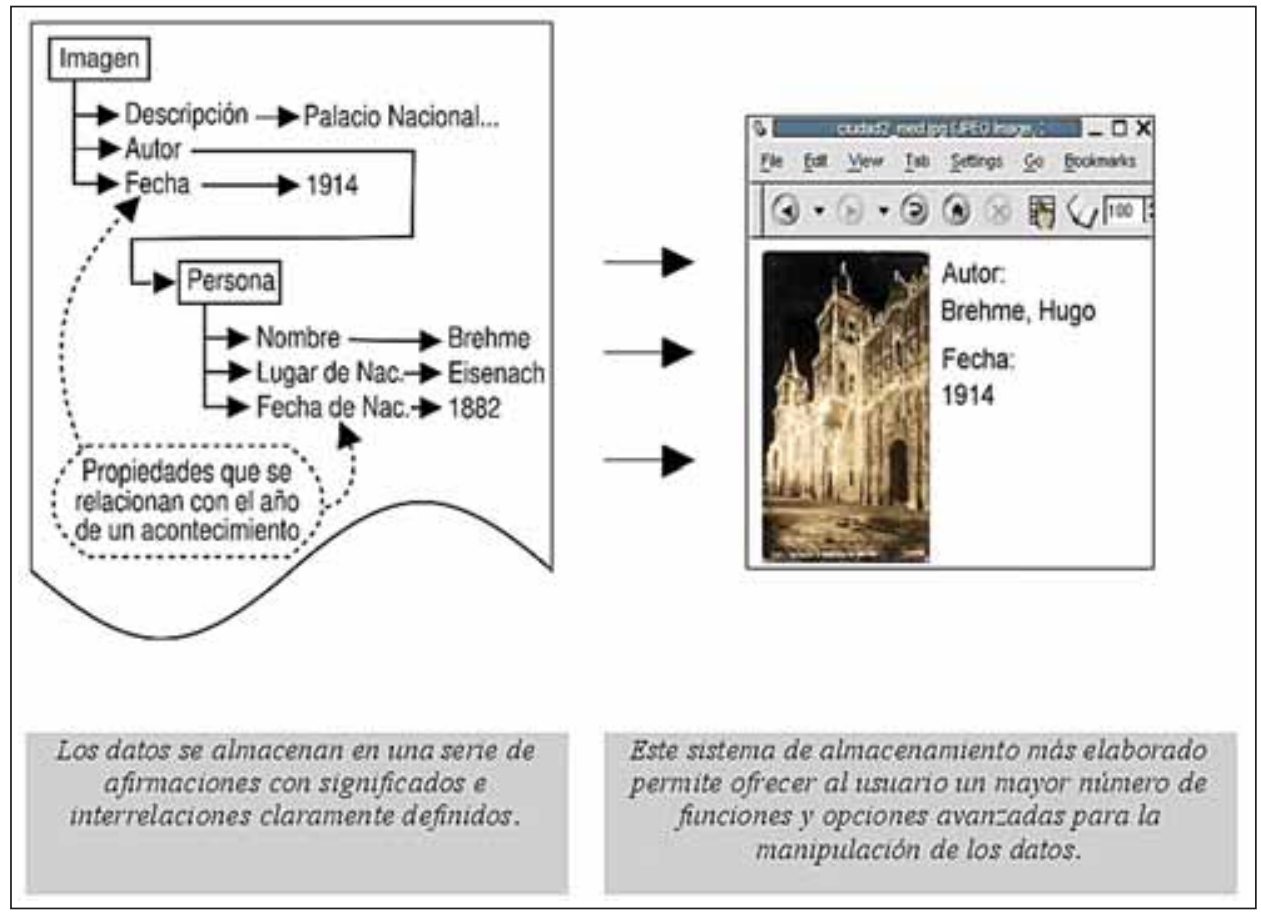

Figura 2 - Estructura de datos en la W S 
- Mayor capacidad y flexibilidad en las búsquedas. El W S permitirá implementar un gran número de opciones para afinar las búsquedas y encontrar rápidamente los datos relevantes.

- Mayor facilidad para exportar los datos hacia otro programa. Se podrán exportar no sólo los datos sino todos los vínculos entre ellos.

- Mayor capacidad de integración con otros conjuntos de datos. Se podrá registrar el parentesco de los conceptos que se emplearán en el SIAF con a quellos de otros sistemas.

- Posibilidad de convertir los datos automáticamente a formatos establecidos (M ARC, Dublin Core, etcétera). EI W S es la tecnología más adecuada para implementar funciones de conversión de este tipo, las cuales usarán los mecanismos genera les de integración de datos ya mencionados.

- Mayor flexibilidad para seguir aumentando la estructura de datos. Al registrar la información en una estructura similar a la que usamos los seres huma nos se fa cilita n las ta rea s subsiguientes de mo difica ción y a ctualización de esa estructura. Este principio ha sido comprobado desde otros ámbitos de la informática, específicamente la programación orientada hacia objetos ${ }^{9}$.

Presentación del prototipo del SIAF

Como ya mencionamos, hemos creado un prototipo del SIAF, el cual implementa un conjunto limitado de las funciones que se necesitarán y sirve como "prueba de concepto", es decir, permite comprobar a grandes rasgos la eficacia del diseño que proponemos. Es importante enfatizar que el prototipo tiene una capacidad reducida en cuanto al número de usuarios y datos que puede manejar. Esto contrasta con la versión del SIAF que funcionará en la fototeca digital, la cual hemos llamado "versión de producción" e integrará todas las funciones que hemos descrito. El objetivo es que, en un primer momento, permita la gestión de al menos un millón de registros y la consulta de 2000 o más usuarios por hora.

La mayoría de los da tos ca ta log rá ficos que se han integ ra do al prototipo fueron elaborados ex profeso para éste; de alguna manera su generación constituyó una prueba de que el SIAF funciona con diferentes procesos de catalogación a ctualmente en uso ${ }^{10}$. A continuación exponemos, por medio de imágenes de pantalla, algunas de las funciones que tiene el prototipo. Como se trata de una aplicación $W$ eb, todas las interacciones con el usuario se dan a tra vés de un navegador W eb (como Internet Explorer o M ozilla). La Figura 3 muestra la página inicial del prototipo, la cual ofrece las opciones de navegar por conjuntos de imágenes y realizar búsquedas sencillas en to do el acervo.

La Figura 4 presenta la primera pantalla que el usuario ve cuando elige revisar un conjunto de imágenes. Del lado izquierdo de la pantalla se despliegan

9. Para más información acerca del WS, véanse las referencias que se incluyen al final de este documento

10. En las imágenes de pantalla también se muestran algunas fichas procedentes de catálogos existentes. Debe recordarse que lo significativo de esta prueba no es la estructura y contenido de las fichas en sí, sino la diversidad de éstas. 
las fotografías mismas, en forma to pequeño, mientras en la columna derecha se presenta una ficha abreviada de cada una de éstas. La forma de mostrarlas fichas - tanto abreviadas como completas - refleja la estructura de la red de significados en la cual éstas se almacenan. En este sentido, lo que el usuario percibe al revisar las fichas es en realidad un fragmento de dicha red; al hacer click sobre los elementos que se presentan en pantalla, se "traslada" a otro fragmento de la red a través de los mismos enlaces que ésta contiene. La Figura 5 muestra una pantalla con la ficha completa de una imagen acompañada por la propia imagen. Las Figuras 6 y 7 presentan dos pasos de una operación de búsqueda en el acervo. En la primera figura, el usuario solicita una búsqueda sobre la palabra "grupo" en cualquier campo que tenga que ver con el contenido de las fotos. La segunda presenta el resultado de dicha búsqueda. Enfatizamos que la versión de producción del SIAF ofrecerá funciones de búsqueda mucho más elaboradas, las cuales permitirán combinar múltiples criterios y operadores, pero en términos generales consideramos que el prototipo, a un con las funciones limitadas que integra, logra demostrar la factibilidad de varios aspectos del proyecto.

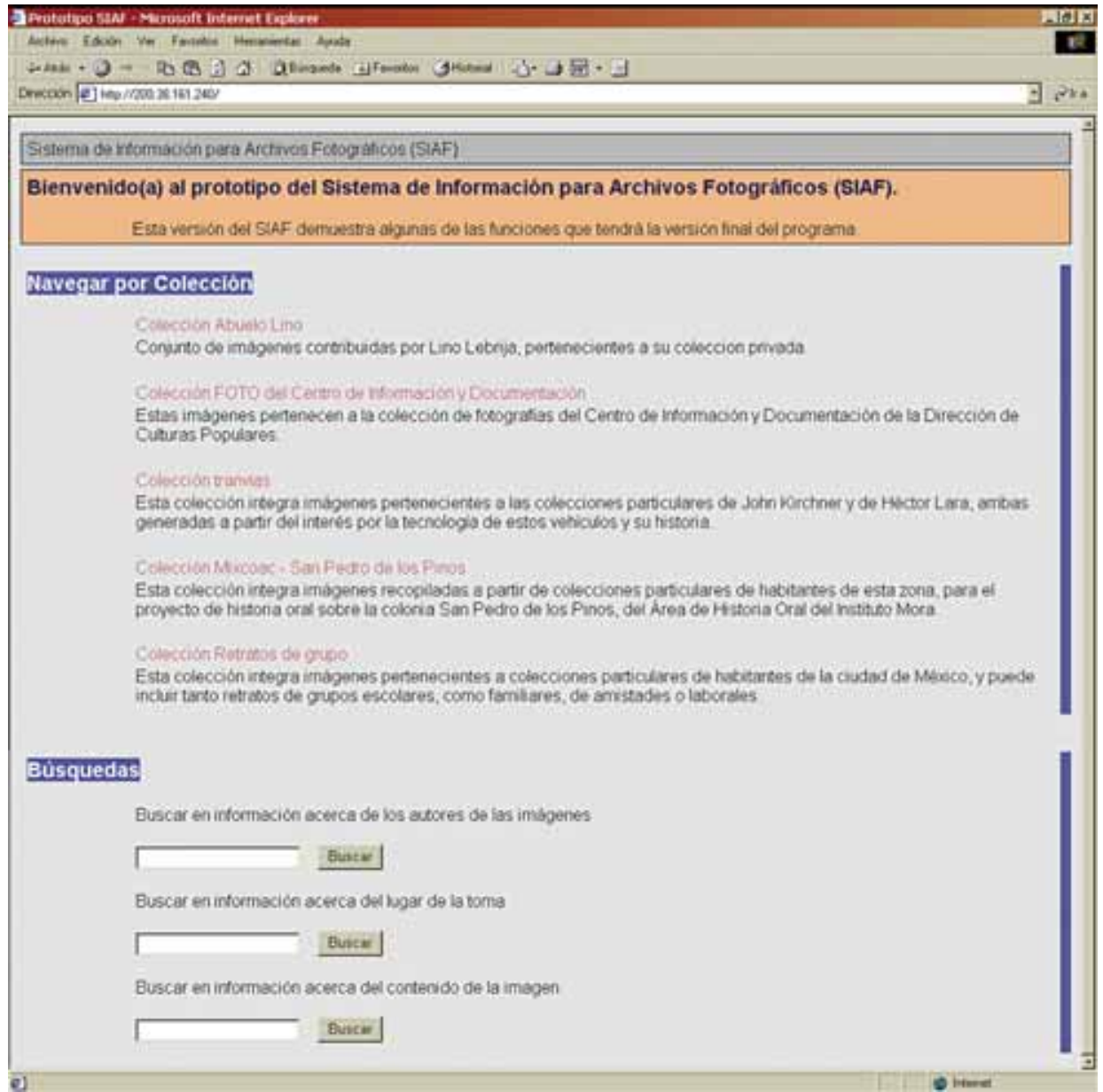

Figura 3 - Página inicial del prototipo. 


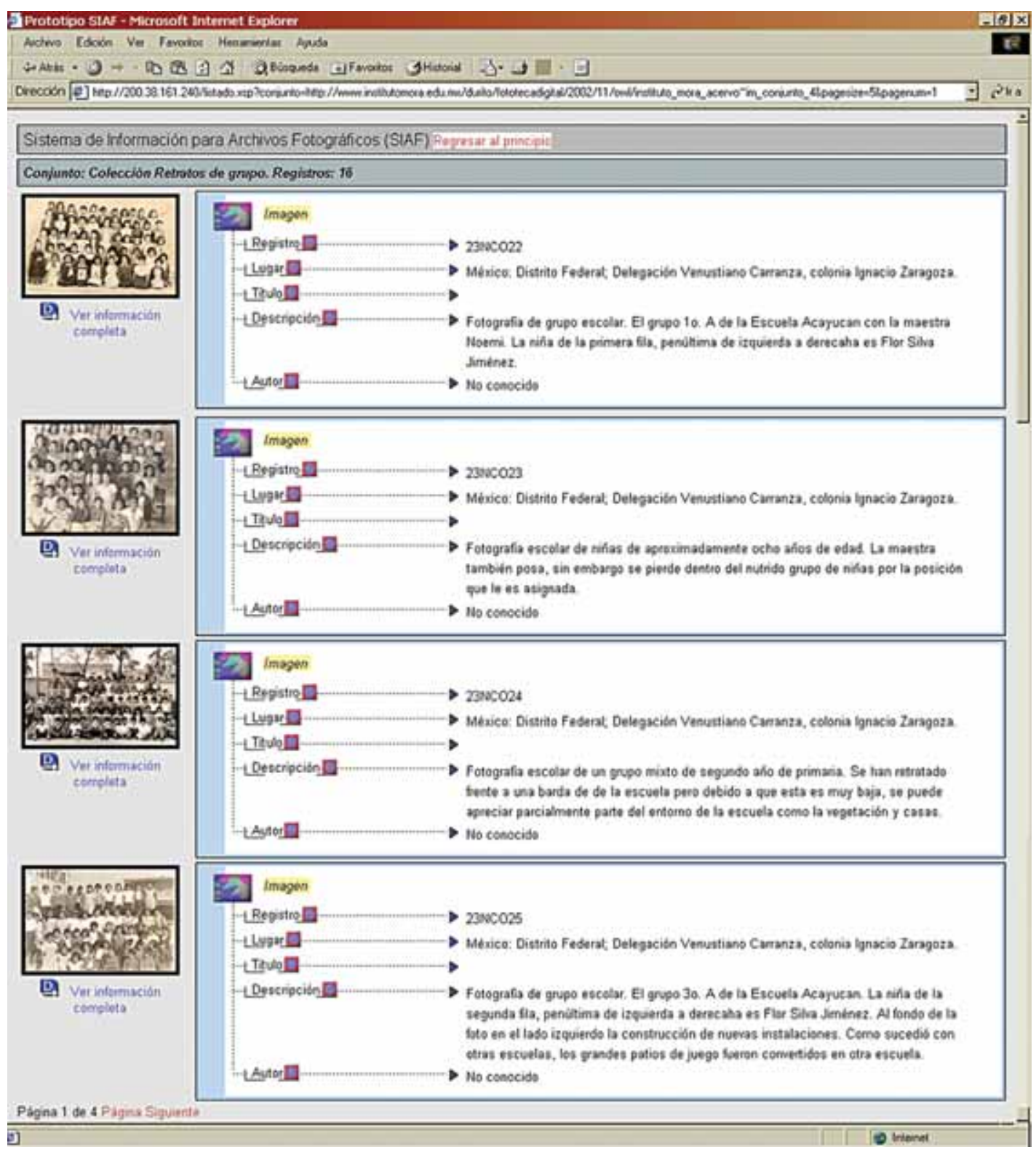

Figura 4 - Conjunto de imágens en la primera pantalla que el usuario ve después de la búsqueda. 


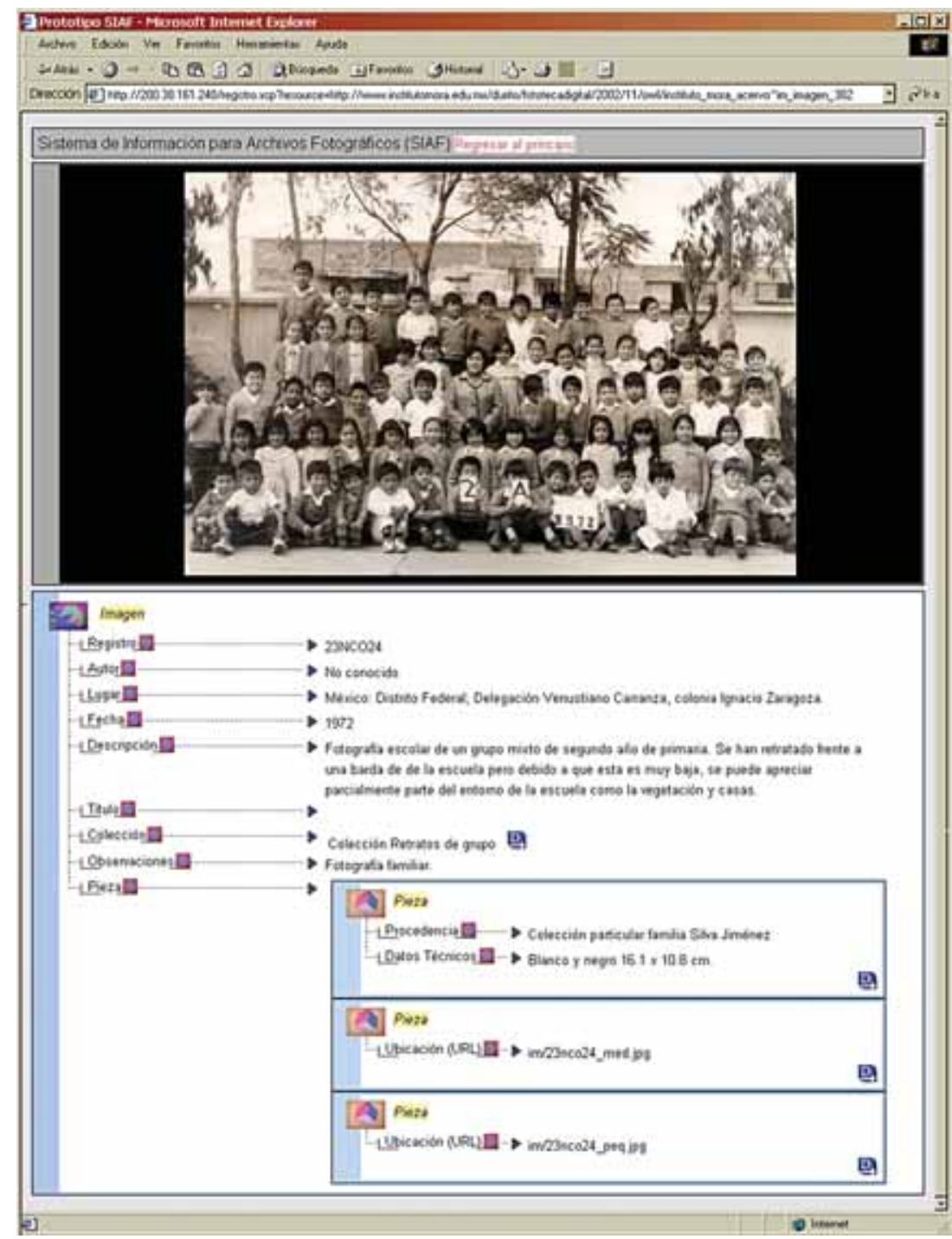

Figura 5 - Pantalla con la ficha completa de una imagen.

\section{Busquedas}

Buscar en información acerca de los autores de las imágenes

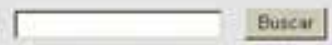

Buscar on informacion acerca del kgar de la toma

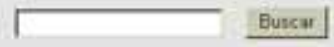

Buscar en información acerca del conterido de la imagen

prupo Buicar

Figura 6 - Pasos de una operación de búsqueda en el acervo sobre la palavra "grupo" 


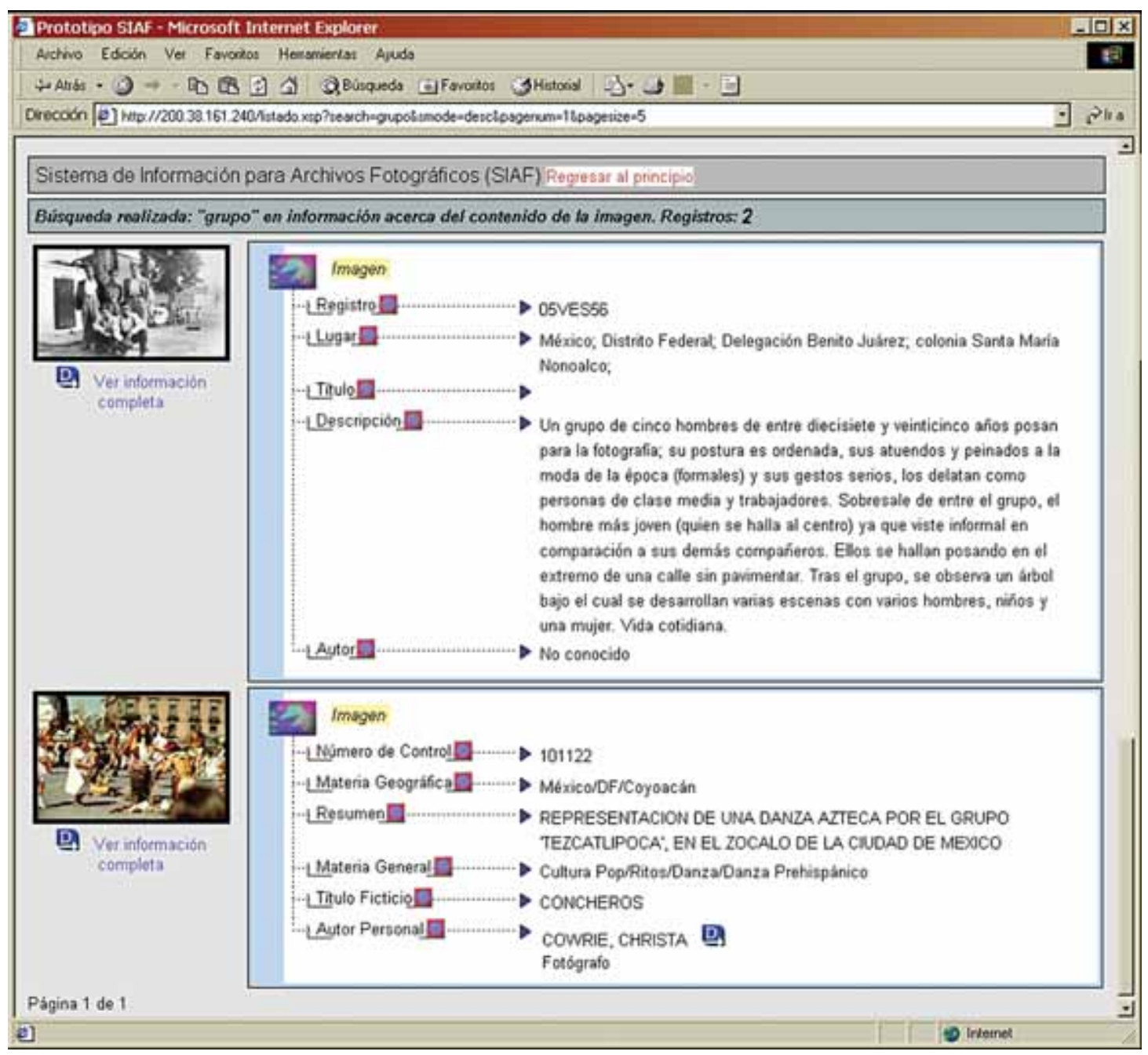

Figura 7 - Resultado de una operación de búsqueda en el acervo 
Para los contenidos de la fototeca digital se contempla la integración de materiales originales procedentes tanto de archivos públicos como de colecciones de particulares.

Habrá casos en que el archivo participante tendrá bajo su responsabilidad la catalogación, captura de datos, digitalización, actualización y preservación de originales. En otros casos - sobre todo de colecciones particula res con recursos limitados - el Instituto M ora o la instancia que establezca un convenio con él para la colaboración en este proyecto se hará responsable de la realización de las primeras de estas tareas y a uxiliará en las labores de preservación.

El Instituto M ora busca con este proyecto promover la investigación social, con el convencimiento de que la informática debe generar propuestas acorde a nuestras preocupaciones y no a las del mercado. El tercer elemento en juego, las ciencias de la documentación, son el campo menos explorado por nosotros; en M éxico hay una falta de investigación en el campo bibliotecológico enfocado a las imágenes en general y en particular a la fotografía. Pensamos que parte del proceso para transforma r el esta do de las imágenes para convertirlas en fuente de conocimiento tiene que ver con la necesaria reflexión en to rno a este campo y, en buena medida, con la modificación de las prácticas de catalogación.

En el marco de este archivo digital, la catalogación se entenderá como un proceso continuo y abierto que se vinculará en todo momento con las labores de investigación. Antes de que se coloquen en línea los materiales de un archivo determinado, se requerirá que éstos cuenten con un grado mínimo de catalogación, el cual constituirá el punto de partida para el desarrollo subsiguiente de la información relacionada con las imágenes.

Es de notar que toda recepción de material tendrá que ir acompañada de la firma de un convenio que establecerá, entre otras cosas, las condiciones para la difusión en Internet de las imágenes y los da tos catalográficos, y señala rá claramente quiénes son los titulares de los derechos de autor y patrimoniales sobre dichos materiales.

Están to davía por definirse los términos y mecanismos específicos del intercambio de observaciones acerca de las imágenes. En todo caso, éstos tendrán que diseñarse en función de los objetivos de investigación social ya expuestos. 
11. En abril de 2003 el programa Apache se usaba en $63 \%$ de los servidores Web. Es difícil calcular exactamente cuántas máquinas emplean un sistema operativo libre, pero todas las estimaciones consideran que son cuando menos varios millones (Véanse los sitios <http:// w w w.hispalinux.es/informes/w heeler/ $>$ y <ht tp://news.netcraft.com y http://ww w.apache. org $>$ ).

12. Esto ha sucedido en México, Brasil, Perú, Taiwan, China, India, Alemania, Reino Unido y Sud África, entre otros lugares. Véase, por ejemplo: Governments push open-source software, $<$ http://news.com.co $\mathrm{m} / 2100-1001-272299$. $\mathrm{html}$ ?legacy $=$ cnet $>\mathrm{y}$ German City GoesEntirely Linux<http://w w w.marketwire.com/ $\mathrm{mw} /$ release $\mathrm{html}$ b1? release_id $=\overline{4} 9691>$.

Las instituciones que han impulsado proyectos de SL son la Unesco, el ConacyT y la Unam.

Con base en este procedimiento se ha creado una cantidad impresionante - literalmente decenas de miles - de programas, con una variedad de usos que van desde los trabajos básicos de oficina hasta el a nálisis de secuencias de genes, pasando por la difusión de sitios Internet, la generación de teoremas matemáticos y los experimentos en la inteligencia artificial. La gran mayoría de este software está disponible sin costo vía Internet.

Impulsado inicialmente desde la academia, el SL ha ido adquiriendo cada vez más importancia en los ámbitos institucionales y la iniciativa privada. Actualmente, millones de computadoras en to do el mundo cuentan con un sistema operativo libre y la mayoría de los servidores Internet emplean $\mathrm{SL}^{11}$. M uchos gobiernos nacionales, regionales y municipales han promovido el uso del SL en la administración pública ${ }^{12}$.

A pesar de las oportunidades que ofrece el SL, la mayoría de los proyectos de creación de acervos computarizados emplean "software de fuente cerrada", es decir, compran o mandan hacer los programas de computadora que necesitan. Pero en esos casos lo que se adquiere no es el software en sí, sino un derecho de uso limitado o "licencia". Se trata de una suerte de contrato 
que debe aceptar el comprador y que le impone restricciones sobre el uso del producto; por ejemplo, se limita el número de veces que se puede reproducir el programa, o se prohíbe modificar las funciones básicas que proporciona. Estas licencias no sólo resultan bastante caras sino que incluso suelen prohibir al usua rio analizar el programa para entender cómo funciona internamente; el no permitir que se conozcan los detalles del funcionamiento de sus programas es parte de la tendencia general de las empresas productoras de software de fuente cerrada, que toman esta medida para proteger su inversión intelectual.

Se ha decidido que no sería apropiado mandar a hacer o crear un programa de fuente cerrada para el presente proyecto, precisamente porque entendemos éste en primer lugar como un proyecto de investigación y creemos que existe una obligación, impuesta por la pretensión de generar conocimiento, de hacer todo lo posible por compartir ampliamente los resultados y los métodos de trabajo. Crear el SIAF bajo una lógica de software de fuente cerrada imposibilitaría la difusión de un resultado importante del trabajo: los detalles del funcionamiento del mismo SIAF.

En cambio, la aplicación de los mecanismos de SL en el desa rrollo del SIAF tiene múltiples ventajas, entre ellas:

- Permitir que todos los aspectos del trabajo se sujeten a las mismas reglas de compartición de la informa ción que se aplican en otras situaciones. No habrá impedimento para difundir las explicaciones sobre cómo funcionará el SIAF.

- Permitir que el proceso de creación del SIAF quede plenamente integrado a las demás labores de investigación.

- Facilitar a los usuarios de programas una adopción más rápida para la gestión de archivos digitales. Se reducirán las barreras para terceros que querrán emplear el SIAF en la gestión de otros sitios $W$ eb de archivos digitales. En específico, la eliminación del costo inicial de una licencia y la posibilidad de adaptar el programa a sus propios fines ayudarán a que otras instituciones e individuos opten por utilizar el SIAF.

- Retroalimentación más rápida y completa. Tanto las personas que usarán el SIAF en otros contextos como los colegas que revisarán los resultados de nuestras investigaciones podrán aportar observaciones acerca del programa con base en un pleno conocimiento de cómo funciona.

- Posibilidad de mejoramiento o a mpliación del programa por terceros. Si otra persona o institución crea una versión modificada del SIAF, tendremos la opción de integrar sus cambios a la versión del programa que empleará la fototeca Digital, siempre que se evalúen pertinentes las modificaciones. 
- Proceso de desarrollo más rápido y económico. Prácticamente todos los programas de computadora se apoyan en "componentes" que son comparables a las piezas de una máquina que pueden ser utilizadas en distintos aparatos y se obtienen prefabricadas. Al emplear un proceso de desarrollo libre, se tiene la posibilidad de integrar al SIAF, sin costo alguno, componentes libres, es decir, componentes que se desarrollan con base en el mismo mecanismo de SL Si se quisiera crear el SIAF como software de fuente cerrada se perdería la posibilidad de usar dichas piezas, lo cual incrementaría sustancialmente el tiempo y costo de todo el proceso.

- Mayor atractivo del proyecto para agencias de financiamiento. La difusión libre de un producto de la investigación podrá resultar de interés para las fundaciones e instituciones en las cuales se buscará apoyo para este proyecto.

Se espera que esta propuesta logre los objetivos mencionados en un corto plazo, y de esta manera contribuya a la profundización del conocimiento y los procesos de investigación acerca de la sociedad.

\section{REFERÊN CIAS}

AARSETH, E.The Field of Humanistic Informatics and its Relation to the Humanities. Espen Aarseth'sWeb Site. Disponible en: <http://w w w.hf.uib.no/hi/espen/HI.html>. Fecha de consulta: 6 mayo 2003.

AGUAYO, F.; ROCA, L. Estudio introductorio. In: Imágenes e investigación social, Mexico, D.F.: Instituto Mora, 2005, p. 9-28.

BERNERS-LEE,T.; HENDLER, J.; ORA, L.The Semantic Web. A new form of Web content that is meaningful to computers will unleash a revolution of new possibilities. ScientificAmerican.com, mayo 2001. Disponible en: <http:// w w w.scientificamerican.com/article. cfm?articlelD=0004814410D2-1C70-84A9809EC588EF21\& catID=2>. Fecha de consulta: 6 mayo 2003.

DU GGAN, H. N. Some Un-Revolutionary Aspects of Computer Editing, Enero 1995. Institute for Advanced Technology in the Humanities. Disponible en: <http://jefferson.village.virginia.edu/ public/hnd/Finneran.html>. Fecha de consulta: 6 mayo 2003.

FLANDERS, J. Editorial Methodology and the Electronic Text. Women Writers Project. Disponible en: <http:// ww p.brow n.edu/encoding/research/NASSR/Argument.html>. Fecha de consulta: junio 2002.

FUNDACIÓN PARA EL SOFTWARE LIBRE. Filosofía del proyecto GNU, feb. 2003. Disponible en: <http://www.org/philosophy/philosophy.es.html>. Fecha de consulta: 6 mayo 2003 
GREEN, A. Cambios actuales en el esquema desupuestos básicos delas prácticas catalográficas. Disponible en: <http://www.nongnu.org/durito/docs/cambios_catalog_green.pdf $>$. Fecha de consulta: 6 mayo 2003.

KUNZ, P. (Ed.). ERCIM News. Special theme: Semantic Web, oct. 2002. Disponible en: $<$ http://www.ercim.org/publication/Ercim_News/enw51/index.html>. Fecha de consulta: 6 mayo 2003.

MCCARTY,W.W hat is humanities computing?Tow ard a definition of the field. Sitio personal de W.McCarty. King's College London, mayo 1998.Disponible en: <http://w w w.kcl.ac.uk/humanities/ cch/w Im/essays/what/ >. Fecha de consulta: 6 mayo 2003.

Poem and algorithm: humanities computing in the life and place of the mind. Sitio personal de W. McCarty. King's College London, enero de 1999. Disponible en: <http://www.kcl.ac.uk/humanities/cch/w Im/essays/poem/>. Fecha de consulta: 6 mayo 2003.

. Humanities computing: Preliminary draft entry for The Encyclopedia of Library and Information Science. Sitio personal deW.McCarty. King's College London, mayo 2002. Disponible en:<http://www.kcl.ac.uk/humanities/cch/w/m/essays/encyc/>. Fecha de consulta:6 mayo 2003.

We would know how we know what we know: Responding to the computational transformation of the humanities. Sitio personal deW.McCarty. King's College London, mayo 1999. Disponible en: <http://www.kcl.ac.uk/humanities/cch/wlm/essays/know/>. Fecha de consulta: 6 mayo 2003.

MCGANN, J.The Rationale of HyperText. Institute for Advanced Technology in the Humanities, mayo 1995 Disponible en: <http://w w w. iath.virginia.edu/public/jjm2f/rationale.html>. Fecha de consulta: 6 mayo 2003.

SINAFO. Normas catalográficas del Sistema Nacional de Fototecas del Inah, CONACULTA-Inah, México, 2000.

SÖDERBERG, J. Copyleft vs. Copyright:A Marxist Critique. First Monday, v. 7, n. 3, marzo 2002. Disponible en: <http://w w w.firstmonday.org/issues/issue7_3/soderberg/index.html>. Fecha de consulta: 6 mayo 2003.

UNSWORTH, JOHN. Documenting the Reinvention of Text:The Importance of Failure. Journal of Electronic Publishing, v. 3, n. 2, dic. 1999. Disponible en:<http://w w w.press.umich.edu/jep/0302/unsw orth.html>. Fecha de consulta: 6 mayo 2003.

.Electronic Scholarship, or, Scholarly Publishing and the Public. Institute for Advanced Technology in the Humanities. Disponible en: <http://www.iath.virginia.edu/ jmu2m/mla94.html>. Fecha de consulta: 6 mayo 2003.

Artigo apresentado em 06/2004. Aprovado em 08/2004. 